University of Nebraska - Lincoln

DigitalCommons@University of Nebraska - Lincoln

$1-1-2004$

\title{
Use of Erythropoietin in Cancer Patients: Assessment of Oncologists' Practice Patterns in the United States and Other Countries
}

\author{
Jared R. Adams \\ Department of Veterans Affairs \\ Linda S. Elting \\ University of Texas M.D. Anderson Cancer Center \\ Gary H. Lyman \\ University of Rochester Medical Center \\ James N. George \\ University of Oklahoma Health Sciences Center \\ Barry C. Lembersky \\ University of Pittsburgh Cancer Institute \\ See next page for additional authors \\ Follow this and additional works at: https://digitalcommons.unl.edu/publichealthresources \\ Part of the Public Health Commons
}

Adams, Jared R.; Elting, Linda S.; Lyman, Gary H.; George, James N.; Lembersky, Barry C.; Armitage, James O.; Demetri, George D.; and Bennett, Charles L., "Use of Erythropoietin in Cancer Patients: Assessment of Oncologists' Practice Patterns in the United States and Other Countries" (2004). Public Health Resources. 2.

https://digitalcommons.unl.edu/publichealthresources/2

This Article is brought to you for free and open access by the Public Health Resources at DigitalCommons@University of Nebraska - Lincoln. It has been accepted for inclusion in Public Health Resources by an authorized administrator of DigitalCommons@University of Nebraska - Lincoln. 


\section{Authors}

Jared R. Adams, Linda S. Elting, Gary H. Lyman, James N. George, Barry C. Lembersky, James 0.

Armitage, George D. Demetri, and Charles L. Bennett 


\title{
SPECIAL ARTICLE
}

\section{Use of Erythropoietin in Cancer Patients: Assessment of Oncologists' Practice Patterns in the United States and Other Countries}

\author{
Jared R. Adams, Linda S. Elting, PhD, Gary H. Lyman, MD, James N. George, MD, \\ Barry C. Lembersky, MD, James O. Armitage, MD, George D. Demetri, MD, \\ Charles L. Bennett, MD, PhD
}

PURPOSE: To assess physician use of erythropoietin in cancer patients before publication of the American Society of Clinical Oncology/American Society of Hematology guidelines.

METHODS: Questionnaires about erythropoietin use in practice and 12 hypothetical clinical scenarios involving patients with cancer were mailed to 2000 oncologists/hematologists in the United States and 19 other countries. Response rates were $30 \%$ in the United States and $25 \%$ internationally. Data on erythropoietin use for ovarian cancer were obtained from one clinical trial. Multivariate regression models assessed predictors of erythropoietin prescription.

RESULTS: Most physicians selected a hemoglobin level $\leq 10$ $\mathrm{g} / \mathrm{dL}$ as an upper threshold for erythropoietin use (36\% to $51 \%$ of U.S. physicians and $21 \%$ to $32 \%$ of foreign physicians). Frequent erythropoietin use (defined as use in at least $10 \%$ of cancer patients) was higher in the United States than elsewhere (adjusted odds ratio $[\mathrm{OR}]=5.8 ; 95 \%$ confidence interval $[\mathrm{CI}]$ :
2.5 to 13.4 ). Among U.S. physicians, those who said they used erythropoietin frequently were more likely to be in fee-for-service than managed care settings ( $\mathrm{OR}=2.2 ; 95 \% \mathrm{CI}$ : 1.3 to 3.7 ). Those who reported never using erythropoietin practiced in countries that had lower annual per capita health care expenditures, lower proportions of privately funded health care, and a national health service ( $P<0.05$ for all comparisons). Of 235 ovarian cancer patients who received topotecan, 38\% (45/118) of U.S. patients and 2\% (2/117) of European patients who developed grade 1 anemia (hemoglobin level between 10 and 12 $\mathrm{g} / \mathrm{dL})$ were treated with erythropoietin $(P<0.01)$.

CONCLUSION: Financial considerations and a hemoglobin level $<10 \mathrm{~g} / \mathrm{dL}$ appear to influence erythropoietin use in the United States, whereas financial considerations alone determine erythropoietin use abroad. Am J Med. 2004;116:28-34.
$\mathrm{R}$ ecombinant human erythropoietin increases red blood cell count and hemoglobin concentration in patients who have anemia associated with cancer or its treatment (1). However, erythropoietin is ex-

From the Department of Veterans Affairs (JRA, CLB), the MidWest Center for Health Services and Policy Research and the Veterans Affairs Chicago Healthcare System/Lakeside Division, Chicago, Illinois; Division of Hematology/Oncology (JRA, CLB), Department of Medicine, Robert H. Lurie Comprehensive Cancer Center (CLB), Center for Health Studies (CLB), Northwestern University Feinberg School of Medicine, Chicago, Illinois; University of Texas M.D. Anderson Cancer Center (LSE), Houston, Texas; University of Rochester Medical Center (GHL), Rochester, New York; University of Oklahoma Health Sciences Center (JNG), Oklahoma City, Oklahoma; University of Pittsburgh Cancer Institute (BCL), Pittsburgh, Pennsylvania; University of Nebraska School of Medicine (JOA), Omaha, Nebraska; and Dana Farber Cancer Institute (GDD), Boston, Massachusetts.

This study was supported by a grant from the Agency for Healthcare Research and Quality (HS 10370).

Requests for reprints should be addressed to Charles L. Bennett, MD, PhD, VA Medical Science Building, 400 E. Ontario, Suite 204, Chicago, Illinois60611, or cbenne@northwestern.edu.

Manuscript submitted August 12, 2002, and accepted in revised form June 23, 2003. pensive and optimal treatment is not known (2). The American Society of Clinical Oncology and the American Society of Hematology jointly requested that the Agency for Healthcare Research and Quality review the use of erythropoietin in oncology and develop guidelines on the subject. The Agency also provided a grant for surveying oncologist preferences for erythropoietin use before publication of the review.

The American Society of Clinical Oncology previously addressed concerns about the benefits of granulocyte and granulocyte-macrophage colony-stimulating factors (36). It surveyed oncologists' preferences for growth factor use and subsequently published evidence-based guidelines (3,7-9). A follow-up survey found that support for these agents decreased in settings that were not supported by the guidelines (8). However, these evaluations did not address international considerations and data on actual patterns of use. We therefore sought to evaluate the preferences of oncologists in the United States and other countries regarding erythropoietin use and to provide data on actual patterns of care. 


\section{METHODS}

Surveys

A random sample of 1500 physicians who practiced in the United States was selected from the American Society of Clinical Oncology membership list and a random sample of 500 physicians who practiced in 19 countries in Europe, Asia, Africa, and the Americas was selected from the Multinational Association for Supportive Care of Cancer membership list. Subjects who failed to respond received a second mailing. Potential respondents who spent fewer than 5 hours per week in practice were instructed to return the questionnaire unanswered. The survey addressed erythropoietin use in 12 hypothetical clinical scenarios in the settings of sarcoma, Hodgkin's disease, and cervical, breast, and ovarian cancer. Vignettes addressed erythropoietin use before, during, and after therapy in fatigued and nonfatigued patients. Physicians were allowed to respond to a vignette that was outside their clinical experience. Support for erythropoietin use was defined as reported use in $\geq 10 \%$ of patients. The survey also included questions on the frequency of erythropoietin use, effect of reimbursement, and whether there were institutional guidelines on erythropoietin use. Information was also obtained on sociodemographic characteristics, including specialty, year of graduation from medical school, practice setting, number of years in practice, and average number of cancer patients seen per week.

Multivariate regression was used to assess factors associated with reported frequent erythropoietin use. The median physician-reported percentage of patients who were prescribed erythropoietin $(<10 \%, 10 \%$ or more $)$ was the dependent variable in the model. Independent predictors included practice setting (private fee-for-service, group-staff health maintenance organization [HMO], or academic group), practice type (oncology, hematology, hematology and oncology), medical school graduation year $(<1970,1970$ or later), local erythropoietin guidelines (yes/no), patients seen per week $(<50,50$ or more), reimbursement denials, and privately funded versus social health care systems.

Because information about practice setting (academic, $\mathrm{HMO}$, private fee-for-service) was not applicable to physicians in other countries, a second analysis assessed the influence of the amount, source, and structure of health care financing for each country on support for erythropoietin use. Multinomial logistic regression was used to identify factors associated with the extremes of practice (always or never using erythropoietin in all 12 vignettes) as compared with a strategy dependent on the clinical setting and hemoglobin level (occasional users). A multilevel model was fit, with physician subjects nested within countries. Candidate factors included sex, practice type, years since graduation, specialty, guideline availability, as well as country-specific information about annual per capita health care expenditure, percentage of health care funded publicly, and the presence of a national health care insurance system (10). Analyses were performed with SAS, version 8.1 (SAS Institute, Cary, North Carolina) using the GENMOD (General Estimating Equations) procedure with an independent covariance matrix.

\section{Patterns of Use}

Data on patterns of use were evaluated for physicians who provided care for women with ovarian cancer, based on usage data obtained from a phase 3 , multicenter, randomized controlled trial conducted in the United States and the United Kingdom between 1997 to 1999 that involved 474 ovarian cancer patients with relapsed or refractory ovarian cancer, all of whom had failed first-line chemotherapy with a platinum-based regimen (11). The study drug regimens consisted of either pegylated liposomal doxorubicin (a 1-hour intravenous infusion of 50 $\mathrm{mg} / \mathrm{m}^{2}$ every 28 days) or topotecan (a 30-minute infusion of $1.5 \mathrm{mg} / \mathrm{m}^{2} / \mathrm{d}$ for 5 consecutive days every 21 days). Approximately half of the patients were treated in the United States and the remaining were treated in Europe. Patient-level data were collected prospectively at the time of erythropoietin prescription during chemotherapy, hemoglobin level at the time of erythropoietin prescription, and duration of erythropoietin administration. During the trial, 28\% (66/235) of patients who were taking topotecan experienced grade 3 or 4 anemia (defined as a hemoglobin level $<8 \mathrm{~g} / \mathrm{dL}$ ) versus $5 \%$ (12/239) who were taking doxorubicin.

\section{RESULTS}

The response rate for the survey was $30 \%(332 / 1108)$ in the United States and 25\% (88/355) internationally. More than half of U.S. respondents practiced in fee-forservice settings, about one third were in academic practices, and about $15 \%$ were in HMO practices (Table 1). About one quarter followed formal erythropoietin guidelines or practiced in settings where guidelines were perceived to influence practice, and approximately half were hematologist/oncologists (Table 1). More physicians in the United States than in other countries reported erythropoietin use in more than 5 patients per week $(53 \%$ [167/316] vs. $10 \%[8 / 80])$.

Physicians in the United States reported that they prescribed erythropoietin to about $20 \%$ of cancer patients (vs. $8 \%$ internationally). Based on the responses to the clinical vignettes, patterns of erythropoietin use were similar among treatment regimens associated with curable versus incurable malignancies (Table 2). Physicians were most supportive of using erythropoietin during chemotherapy versus either before initiating or after completion of chemotherapy. The maximum hemoglobin threshold for erythropoietin use was most often $10 \mathrm{~g} / \mathrm{dL}$. Across clinical vignettes, physicians were consistent 
Table 1. Demographic and Practice Characteristics of Physicians from the United States and Other Countries Who Participated in the Erythropoietin Survey

\begin{tabular}{lrr}
\hline \multicolumn{1}{c}{ Characteristic } & $\begin{array}{r}\text { Physicians in the United States } \\
(\mathrm{n}=332)\end{array}$ & $\begin{array}{c}\text { Physicians in Other Countries } \\
(\mathrm{n}=88)\end{array}$ \\
\hline & & Number (\%) \\
\cline { 2 - 3 } Type of practice & & Not available \\
Academic & $91(27)$ & Not applicable \\
Health maintenance organization & $49(14)$ & Not applicable \\
Fee-for-service & $198(59)$ & $18(20)$ \\
Medical school graduation before 1970 & $76(23)$ & $44(50)$ \\
See $>50$ cancer patients per week & $232(70)$ & $27(33)$ \\
Hematology/oncology & $161(50)$ & $16(18)$ \\
Work with formal erythropoietin practice guideline & $85(25)$ & $8(10)$ \\
Order erythropoietin for $>5$ patients per week & $167(53)$ & \\
\hline
\end{tabular}

* Percentages based on 316 physicians in the United States and 80 physicians in other countries.

about whether they never used erythropoietin, or supported erythropoietin prophylaxis, i.e., in patients with hemoglobin levels $\geq 12 \mathrm{~g} / \mathrm{dL}$.

In the United States, several factors were associated with frequent $(\geq 10 \%)$ prescribing of erythropoietin, including being a hematologist/oncologist (adjusted odds ratio $[\mathrm{OR}]=1.6 ; 95 \%$ confidence interval $[\mathrm{CI}]: 2.5$ to 13.4) and practicing in a fee-for-service setting ( $\mathrm{OR}=$ 2.2; $95 \%$ CI: 1.3 to 3.7). Frequent erythropoietin use was much higher in the United States than in other countries $(\mathrm{OR}=5.8 ; 95 \% \mathrm{CI}: 2.5$ to 13.4$)$. Physicians in the United States showed a greater preference for erythropoietin use, particularly before initiating chemotherapy in patients with ovarian cancer (68\% [198/295] vs. $42 \%$ [34/80]), at any hemoglobin threshold during treatment (95\% [292/ $308]$ vs. $68 \%$ [54/80]), after treatment in patients with stable disease ( $82 \%$ [254/308] vs. $48 \%$ [38/80]), and for ever use (94\% [289/308] vs. $68 \%$ [54/80]; $P<0.001$ for each comparison).

Of U.S. respondents, 37\% (108/315) reported that financial considerations had affected the decision to use erythropoietin at least once in their practice. Physicians in fee-for-service settings ( $\mathrm{OR}=3.0 ; 95 \% \mathrm{CI}$ : 1.6 to 5.5 ) and who prescribed erythropoietin frequently $(\mathrm{OR}=1.9$; 95\% CI: 1.1 to 3.4 ) were most likely to have withheld erythropoietin treatment because of reimbursement considerations. Physicians who reported never using erythropoietin were more likely to practice in countries where the annual per capita health care expenditure was low, where a large proportion of health care costs was funded from public sources, and where there was a national health insurance program (Table 3; $P<0.05$ for each parameter). The opposite was true of physicians who always supported the use of erythropoietin (Table 3).

Patterns of Erythropoietin Use in Ovarian Cancer In the clinical trial of second-line chemotherapy with topotecan or doxorubicin in patients with ovarian cancer, no topotecan-treated patient received erythropoietin before the initiation of the first cycle of treatment. Of topotecan-treated patients, $38 \%$ (45/118) of U.S. patients versus $2 \%(2 / 117)$ of European patients were treated with erythropoietin $(P<0.01)$. Physicians in the United States frequently initiated erythropoietin treatment during the third cycle of topotecan chemotherapy, often following one to two cycles of anemia. At the time of erythropoietin initiation, 27\% $(\mathrm{n}=33)$ of patients in the United States had a hemoglobin level between 10 and $12 \mathrm{~g} / \mathrm{dL}, 62 \%$ ( $=73)$ had a level between 8 and $10 \mathrm{~g} / \mathrm{dL}$, and $10 \%(\mathrm{n}=$ 12) had a level $<8 \mathrm{~g} / \mathrm{dL}$. The most common hemoglobin level at erythropoietin prescription was $9.5 \mathrm{~g} / \mathrm{dL}$. The average duration of erythropoietin use was 16 weeks during the entire course of therapy for patients who were treated in the United States. Due to the low incidence of anemia in the pegylated liposomal doxorubicin arm, erythropoietin use was lower. Of all 474 enrolled ovarian cancer patients, $37 \%(56 / 150)$ of U.S. patients and $2 \%(2 / 122)$ of European patients who developed any grade anemia (hemoglobin $<12 \mathrm{~g} / \mathrm{dL})$ were treated with erythropoietin $(P$ $<6.01)$.

\section{DISCUSSION}

Erythropoietin improves hemoglobin levels and reduces transfusion requirements among cancer patients $(2,12,13)$. Its use remains controversial, however, partly because of the paucity of data to support a quality-of-life or survival benefit $(12,13)$. Moreover, it is unclear how much value any health care system places on subjective patient-reported endpoints such as quality-of-life parameters. Our results indicate that oncologists in the United States support erythropoietin use in cancer patients who have a serum hemoglobin level $\leq 10 \mathrm{~g} / \mathrm{dL}$, whereas oncologists in other countries are far less supportive of its use in this setting. Moreover, U.S. oncolo- 
Table 2. Maximum Hemoglobin Threshold for Prescription of Erythropoietin among Surveyed Oncologists Who Practiced in the United States or Other Countries

\begin{tabular}{|c|c|c|c|c|c|c|c|c|c|c|c|c|}
\hline \multirow[b]{3}{*}{$\begin{array}{l}\text { Hemoglobin } \\
\text { Threshold }\end{array}$} & \multicolumn{12}{|c|}{ Setting for Clinical Practice } \\
\hline & \multicolumn{3}{|c|}{ Hodgkin's Disease } & \multirow{2}{*}{ 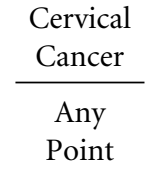 } & \multicolumn{2}{|c|}{ Breast Cancer } & \multicolumn{2}{|c|}{ Ewing Sarcoma } & \multicolumn{4}{|c|}{ Ovarian Cancer } \\
\hline & $\begin{array}{c}\text { Before } \\
\text { Chemotherapy }\end{array}$ & $\begin{array}{l}\text { Before } \\
\text { Cycle } 2\end{array}$ & $\begin{array}{l}\text { After } \\
\text { Therapy }\end{array}$ & & $\begin{array}{c}\text { Before } \\
\text { Chemotherapy }\end{array}$ & $\begin{array}{l}\text { Before } \\
\text { Cycle } 3\end{array}$ & 3 Months & 6 Months & $\begin{array}{c}\text { Before } \\
\text { Chemotherapy }\end{array}$ & $\begin{array}{l}\text { Before } \\
\text { Cycle } 2\end{array}$ & $\begin{array}{c}\text { After Stable } \\
\text { Disease }\end{array}$ & $\begin{array}{c}\text { After Progressive } \\
\text { Disease }\end{array}$ \\
\hline $\begin{array}{l}\text { United States } \\
\qquad(\mathrm{n}=332)\end{array}$ & $(\mathrm{n}=298)$ & $(\mathrm{n}=308)$ & $(\mathrm{n}=306)$ & $(\mathrm{n}=296)$ & $(\mathrm{n}=306)$ & $(\mathrm{n}=314)$ & $(\mathrm{n}=300)$ & $(\mathrm{n}=304)$ & $(\mathrm{n}=295)$ & $(\mathrm{n}=308)$ & $(\mathrm{n}=310)$ & $(\mathrm{n}=308)$ \\
\hline $12 \mathrm{~g} / \mathrm{dL}$ & $6(2)$ & $18(6)$ & $15(5)$ & $18(6)$ & $12(4)$ & $28(9)$ & $18(6)$ & $36(12)$ & $12(4)$ & $22(7)$ & $16(5)$ & $22(7)$ \\
\hline $11 \mathrm{~g} / \mathrm{dL}$ & $36(12)$ & 59 (19) & $40(13)$ & $50(17)$ & $55(18)$ & $79(25)$ & $42(14)$ & $64(21)$ & $53(18)$ & $65(21)$ & $37(12)$ & 59 (19) \\
\hline $10 \mathrm{~g} / \mathrm{dL}$ & $149(50)$ & $126(41)$ & $110(36)$ & $112(38)$ & $144(47)$ & $132(42)$ & $105(35)$ & $116(38)$ & $130(44)$ & $132(43)$ & $118(38)$ & $142(46)$ \\
\hline $9 \mathrm{~g} / \mathrm{dL}$ & 0 & $68(22)$ & $64(21)$ & $56(19)$ & 0 & $53(17)$ & $69(23)$ & $61(20)$ & 0 & $55(18)$ & $56(18)$ & $59(19)$ \\
\hline $8 \mathrm{~g} / \mathrm{dL}$ & 0 & $18(6)$ & $28(9)$ & $9(3)$ & 0 & $9(3)$ & $33(11)$ & $9(6)$ & 0 & $18(6)$ & $31(10)$ & $9(3)$ \\
\hline No erythropoietin & $107(36)$ & $18(6)$ & $49(16)$ & $50(17)$ & $95(31)$ & $13(4)$ & $33(11)$ & $9(3)$ & $100(34)$ & $15(5)$ & $53(17)$ & $18(6)$ \\
\hline $\begin{array}{l}\text { Other Countries } \\
\qquad(\mathrm{n}=88)\end{array}$ & $(\mathrm{n}=72)$ & $(\mathrm{n}=78)$ & $(\mathrm{n}=77)$ & $(\mathrm{n}=79)$ & $(\mathrm{n}=75)$ & $(\mathrm{n}=80)$ & $(\mathrm{n}=75)$ & $(\mathrm{n}=75)$ & $(\mathrm{n}=78)$ & $(\mathrm{n}=80)$ & $(\mathrm{n}=80)$ & $(\mathrm{n}=80)$ \\
\hline $12 \mathrm{~g} / \mathrm{dL}$ & $1(1)$ & $2(3)$ & $2(3)$ & $2(3)$ & $4(5)$ & $4(5)$ & $5(7)$ & $6(8)$ & $4(5)$ & $5(6)$ & $2(3)$ & $5(6)$ \\
\hline $11 \mathrm{~g} / \mathrm{dL}$ & $4(6)$ & $7(9)$ & $5(7)$ & 15 (19) & $9(12)$ & $14(17)$ & $9(12)$ & $14(19)$ & $9(12)$ & $12(15)$ & $7(9)$ & $10(12)$ \\
\hline $10 \mathrm{~g} / \mathrm{dL}$ & $19(27)$ & $20(26)$ & $15(20)$ & $15(19)$ & $24(32)$ & $24(30)$ & $20(26)$ & $19(25)$ & $18(23)$ & $19(24)$ & $16(20)$ & $25(31)$ \\
\hline $9 \mathrm{~g} / \mathrm{dL}$ & 0 & $17(22)$ & $10(13)$ & $1(1)$ & 0 & $8(10)$ & $11(15)$ & $17(22)$ & 0 & $10(12)$ & $9(11)$ & $11(14)$ \\
\hline $8 \mathrm{~g} / \mathrm{dL}$ & 0 & $6(8)$ & $9(12)$ & $4(5)$ & 0 & $4(5)$ & $8(11)$ & $5(6)$ & 0 & $10(8)$ & $3(4)$ & $4(5)$ \\
\hline No erythropoietin & $48(66)$ & $25(32)$ & $35(45)$ & $42(53)$ & $38(51)$ & $26(33)$ & $22(29)$ & $15(20)$ & $47(60)$ & $26(33)$ & $42(53)$ & $26(32)$ \\
\hline
\end{tabular}


Table 3. Erythropoietin Use, by Type of Health Care Financing*

\begin{tabular}{|c|c|c|c|c|}
\hline Health Care Financing Parameter ${ }^{\dagger}$ & $\begin{array}{l}\text { Never Use } \\
\text { Erythropoietin } \\
\quad(\mathrm{n}=26)\end{array}$ & $\begin{array}{l}\text { Always Use } \\
\text { Erythropoietin } \\
\quad(\mathrm{n}=189)\end{array}$ & $\begin{array}{l}\text { Sometimes Use } \\
\text { Erythropoietin } \\
\quad(\mathrm{n}=205)\end{array}$ & $P$ Value ${ }^{\ddagger}$ \\
\hline & \multicolumn{4}{|c|}{ Number $(\%)$} \\
\hline Annual per capita health care expenditure & & & & $<0.02$ \\
\hline$<\$ 1000$ & $13(50)$ & $18(9)$ & $42(20)$ & \\
\hline$\$ 1000-\$ 3000$ & $4(15)$ & $1(1)$ & $12(6)$ & \\
\hline$>\$ 3000$ & $9(35)$ & $170(90)$ & $151(74)$ & \\
\hline National health insurance program & $16(60)$ & $19(10)$ & $60(28)$ & $<0.04$ \\
\hline Public funding for health care & & & & $<0.001$ \\
\hline $0 \%-50 \%$ & $10(39)$ & $169(89)$ & $143(70)$ & \\
\hline$>50 \%$ & $16(61)$ & $20(11)$ & $62(30)$ & \\
\hline
\end{tabular}

* Based on entire data set including all countries. A nested regression model was used to adjust for clustering by country.

${ }^{\dagger}$ Data from the World Health Organization (10).

${ }^{\ddagger} P$ values calculated by multilevel multinomial logistic regression. Additional covariates in the model included sex, practice type, years since graduation, specialty, and guideline availability.

gists who practice in fee-for-service settings are more likely than those who practice in managed care settings to support erythropoietin use. Overall, higher support for erythropoietin use was associated with several countrylevel factors, including higher levels of private medicine, the absence of national health insurance programs, and larger global health budgets.

Economic and clinical considerations appear to influence the decision to use erythropoietin. Evidence-based reviews and guidelines are most supportive of erythropoietin use in chemotherapy patients who have hemoglobin levels $<10 \mathrm{~g} / \mathrm{dL}(2,12,13)$, which was also the setting in which U.S. survey respondents and U.S. oncologists in the ovarian cancer study were most likely to support erythropoietin use. In contrast, physicians in other countries were less supportive of erythropoietin use. These differences have economic implications. For example, the mean cost of anemia treatment for patients who received topotecan in the ovarian cancer study was $\$ 3507$ greater in the United States than in Europe ( $\$ 4839$ vs. \$1432), primarily because of international differences in expenditures on erythropoietin per patient (mean of $\$ 3490$ vs. \$242), whereas expenditures for packed red blood cells were similar (\$1346 vs. \$1190) (14). However, overall survival rates, disease-free survival rates, and quality-oflife outcomes were virtually identical for the ovarian cancer patients who received care in the United States versus Europe (11). Almost two thirds of erythropoietin use for patients who received care in the United States occurred among women with a hemoglobin level $<10 \mathrm{~g} / \mathrm{dL}$, which is similar to the $67 \%$ rate reported by U.S. oncologists in our survey. Furthermore, the preference to use erythropoietin in cancer patients with mild anemia in the United States is consistent with Medicare reimbursement policies. In fact, reimbursement policies could be a major determinant of the practice patterns and preferences of physicians. Almost all of the state Medicare carriers require documentation of a hemoglobin level $\leq 10 \mathrm{~g} / \mathrm{dL}$ before reimbursing for erythropoietin use. In other countries, reimbursement policies for erythropoietin differ markedly. We found significantly lower levels of support for erythropoietin use among respondents from countries that have national health insurance programs, large publicly funded health care systems, or low per capita health care expenditures.

The study design addressed limitations identified in previous surveys of colony-stimulating factor use. Data on patterns of use were obtained to complement the survey scenario for women with ovarian cancer. The clinical trial results and the survey both identified infrequent use of erythropoietin before initiation of the first cycle of chemotherapy, infrequent use of prophylactic erythropoietin for patients who were not anemic, and use for ovarian cancer in almost two thirds of patients after hemoglobin levels decreased to $<10 \mathrm{~g} / \mathrm{dL}$. The survey results and data on patterns of use also included assessments from international settings. Researchers from France and the United States previously identified greater use of cytokines in the clinical practice setting in the United States than in France $(15,16)$, which is similar to that reported in the current study.

The survey findings indicate that support for erythropoietin use in the United States was higher in the fee-forservice than managed care setting, mirroring that which has been reported previously for other cytokines. Physicians in the fee-for-service setting more often supported the use of erythropoietin and granulocyte and granulocyte-macrophage colony-stimulating factor for each of the clinical scenarios than did managed care physicians. The surveys also showed greater support among fee-forservice physicians for use of colony-stimulating factors in the setting of curative and palliative treatments and in 
persons with solid tumors, leukemia, and lymphoma (79). Although it is not known if reimbursement considerations can partly explain these variations in cytokine use, respondents to both surveys on erythropoietin and colony-stimulating factor use reported that reimbursement denials were common.

Lastly, the issues identified in this study regarding erythropoietin use-the high variation in prescription rates, the large potential economic impact of chronic overuse, the uncertainty about optimal treatment, and the identification of ethical considerations-may be useful in directing evidence-based clinical guidelines. The purpose of this study was to measure baseline practice variations and predictors of overuse before the release of the American Society of Clinical Oncology/American Society of Hematology guidelines to possibly target dissemination and assess efficacy of guideline publication. The guideline panel supported erythropoietin use as a treatment option for patients with chemotherapy-associated anemia who had a hemoglobin level $<10 \mathrm{~g} / \mathrm{dL}$ (Appendix). Use of erythropoietin in patients with "less severe anemia (hemoglobin $<12 \mathrm{~g} / \mathrm{dL}$ but never below 10 $\mathrm{g} / \mathrm{dL})$.. . should be determined by clinical circumstances" (17). We found that $38 \%$ of erythropoietin prescription occurred before hemoglobin levels crossed the cutoff of $10 \mathrm{~g} / \mathrm{dL}$, indicating room for improvement.

This study has several limitations. First, the survey response rate was lower than in the two previous surveys of colony-stimulating factors $(7,8)$, and was most likely related to the short period for conducting the survey. A follow-up survey of erythropoietin use is planned to follow the recent publication of evidence-based guidelines (13), and a higher response rate is anticipated because respondents will have 4 to 6 months to respond. Indeed, prior surveys with relatively long response periods and a series of follow-up telephone calls $(8,9,18)$ have response rates that are notably greater than those in surveys with shorter response periods (7). Second, we assessed actual practice patterns of erythropoietin prescription only in one of the five disease settings described in the surveyovarian cancer. Third, several differences between the clinical trial and the survey limit direct comparison, such as the unit of analysis, which was at the physician level in the survey and at the patient level in the clinical trial. In the clinical trial, patients would commonly have one or two anemic cycles before erythropoietin was prescribed. In contrast, the survey assessed the physician's maximum tolerance before prescribing erythropoietin. Six percent of physicians surveyed reported that they would never prescribe erythropoietin; in the clinical trial, $62 \%$ of patients with grades 2 to 4 anemia were not treated with erythropoietin. However, most physicians' maximum tolerance for erythropoietin prescription was at a hemoglobin level $\leq 10 \mathrm{~g} / \mathrm{dL}$, as was observed in the trial, where hemoglobin level was often $9.5 \mathrm{~g} / \mathrm{dL}$ when erythropoietin was prescribed. Finally, evidence of a quality-of-life benefit with erythropoietin was reported in a phase 3 trial that was published following our survey and the publication of the clinical guidelines $(17,19)$.

In conclusion, financial considerations and a hemoglobin level $<10 \mathrm{~g} / \mathrm{dL}$ appear to be the principal determinants of erythropoietin use in the United States, as compared with in other countries where financial considerations alone appear to determine use. It would be useful to re-evaluate the patterns of erythropoietin use following the publication of the recent guidelines (17).

\section{REFERENCES}

1. Goodnough LT, Monk TG, Andriole GL. Erythropoietin therapy. N Engl J Med. 1997;336:933-938.

2. Seidenfeld J, Piper M, Flamm C, et al. Erythropoietin treatment of anemia associated with cancer therapy: a systematic review and meta-analysis of controlled clinical trials. J Natl Cancer Inst. 2001; 93:1204-1214

3. American Society of Clinical Oncology. Recommendations for the use of hematopoietic colony-stimulating factors. Evidenced-based clinical practice guidelines. J Clin Oncol. 1994;12:2471-2508.

4. Ozer H, Armitage JO, Bennett CL, et al. 2000 Update of recommendations for the use of hematopoietic colony-stimulating factors: evidence-based, clinical practice guidelines. J Clin Oncol. 2000;18: 3558-3585.

5. Glaspy JA. Economic outcomes associated with the use of hematopoietic growth factors. Oncology. 1995;9(suppl):S93-S105.

6. Lyman GH, Lyman CG, Sanderson RA, et al. Decision analysis of hematopoietic growth factor use in patients receiving cancer chemotherapy. J Natl Cancer Inst. 1992;85:488-493.

7. Bennett CL, Smith TJ, Weeks JC, et al. Use of hematopoietic colony stimulating factors: the American Society of Clinical Oncology survey. J Clin Oncol. 1996;14:2511-2520.

8. Bennett CL, Weeks JA, Somerfield MR, et al. Use of hematopoietic colony-stimulating factors: comparison of the 1994 and 1997 American Society of Clinical Oncology Surveys regarding ASCO clinical practice guidelines. J Clin Oncol. 1999;17:3676-3681.

9. Bennett CL, Bishop MR, Tallman MS, et al. The association between physician reimbursement in the USA and use of hematopoietic colony stimulating factors as adjunct therapy for older patients with acute myeloid leukemia: results from the 1997 American Society of Clinical Oncology survey. Ann Oncol. 1999;10:1355-1359.

10. World Health Organization. World Health Report 2000-Health Systems: Improving Performance. Geneva, Switzerland: World Health Organization; 2001.

11. Gordon AN, Fleagle JT, Guthrie D, et al. Recurrent epithelial ovarian carcinoma: a randomized phase III study of pegylated liposomal doxorubicin versus topotecan. J Clin Oncol. 2001;20:3312-3322.

12. Aronson N, Seidenfeld J, Piper MA, et al. Use of Erythropoietin in Oncology. Evidence Report/Technology Assessment No. 30. Prepared by the Blue Cross and Blue Shield Association Evidencebased Practice Center under Contract No. 290-97-0015. Rockville, Maryland: Agency for Healthcare Research and Quality; June 2001. AHRQ Publication No. 01-E009.

13. Gordon MS, Lichtin AE, Woolf SH, et al. Use of erythropoietin in patients with cancer: evidence-based clinical practice guidelines of the American Society of Clinical Oncology and American Society of Hematology. J Clin Oncol. 2002;20:4083-4107.

14. Smith DH, Adams JR, Johnston SRD, et al. A comparative economic analysis of pegylated liposomal doxorubicin versus topotecan in ovarian cancer in the USA and the UK. Ann Oncol. 2002;13: $1590-1597$. 
15. Debrix I, Madelaine I, Grenet N, et al. Impact of ASCO guidelines for the use of hematopoietic colony stimulating factors (CSFs): survey results of fifteen Paris university hospitals. Pharm World Sci. 1999;21:270-271.

16. Swanson G, Bergstrom K, Stump A, et al. Growth factor usage patterns and outcomes in the community setting: collection through a practice-based computerized clinical information system. J Clin Oncol. 2000;18:1764-1770.

17. Rizzo JD, Lichter AE, Woolf AH, et al. Use of epoetin in patients with cancer: evidence-based clinical practice guidelines of the
American Society of Clinical Oncology and the American Society of Hematology. J Clin Oncol. 2002;20:4083-4107.

18. Bennett CL, Somerfield MR, Pfister DG, et al. Perspectives on the value of ASCO clinical guidelines as reported by oncologists and HMOs. J Clin Oncol. 2003;21:937-941.

19. Littlewood TJ, Bajetta E, Nortier JWR, Vercammen E, Rapoport B. Effects of epoetin alfa on hematologic parameters and quality of life in cancer patients receiving nonplatinum chemotherapy: results of a randomized, double-blind, placebo-controlled trial. J Clin Oncol. 2001;19:2865-2874.

\section{APPENDIX}

Summary of evidence-based clinical practice guidelines of the American Society of Clinical Oncology and the American Society of Hematology*

1. The use of epoetin is recommended as a treatment option for patients with chemotherapy-associated anemia and a hemoglobin concentration that has declined to a level $\leq 10 \mathrm{~g} / \mathrm{dL}$. Red blood cell transfusion is also an option depending on the severity of anemia or clinical circumstances.

2. For patients with declining hemoglobin levels but less severe anemia (hemoglobin level $<12 \mathrm{~g} / \mathrm{dL}$ but $>10 \mathrm{~g} / \mathrm{dL}$ ), the decision of whether to use epoetin immediately or to wait until hemoglobin levels fall closer to $10 \mathrm{~g} / \mathrm{dL}$ should be determined by clinical circumstances. Red blood cell transfusion is also a therapeutic option in severe clinical conditions.

3. The recommendations are based on evidence from trials in which epoetin was administered subcutaneously three times weekly. The recommended starting dose is $150 \mathrm{U} / \mathrm{kg}$ given three times weekly for a minimum of 4 weeks, with consideration given for dose escalation to $300 \mathrm{U} / \mathrm{kg}$ three times weekly for an additional 4 to 8 weeks in those who do not respond to the initial dose. Although supported by less strong evidence, an alternative weekly dosing regimen (40,000 U per week), based on common clinical practice, can be considered. Dose escalation of weekly regimens should be under similar circumstances to thrice-weekly regimens.

4. Continuing epoetin treatment beyond 6 to 8 weeks in the absence of response (e.g., increase of $<1$ to 2 g/dL in hemoglobin level), assuming that appropriate dose increase has been attempted in nonresponders, does not appear to be beneficial. Patients who do not respond should be investigated for underlying tumor progression or iron deficiency. As with other unsuccessful treatments, consideration should be given to discontinuing the medication.

5. Hemoglobin levels can be raised to (or near) a concentration of $12 \mathrm{~g} / \mathrm{dL}$, at which time the dosage of epoetin should be titrated to maintain that level or restarted when the level falls to near $10 \mathrm{~g} / \mathrm{dL}$. Insufficient evidence to date supports the "normalization" of hemoglobin levels to above $12 \mathrm{~g} / \mathrm{dL}$.

6. Baseline and periodic monitoring of iron, total iron-binding capacity, transferrin saturation, or ferritin levels, and instituting iron repletion when indicated, may be useful in limiting the need for epoetin, maximizing symptomatic improvement for patients, and determining the reason for failure to respond to epoetin. There is inadequate evidence to specify the optimal timing, periodicity, or testing regimen for such monitoring.

7. There is evidence from one well-designed, placebo-controlled, randomized trial that supports the use of epoetin in patients with anemia associated with low-risk myelodysplasia, but there are no published high-quality studies to support its use in patients with anemic myeloma, non-Hodgkin's lymphoma, or chronic lymphocytic leukemia in the absence of chemotherapy. Treatment with epoetin in myeloma, non-Hodgkin's lymphoma, or chronic lymphocytic leukemia patients experiencing chemotherapy-associated anemia should follow the recommendations outlined above.

8. Physicians caring for patients with myeloma, non-Hodgkin's lymphoma, or chronic lymphocytic leukemia are advised to begin treatment with chemotherapy or corticosteroids and to observe the hematologic outcomes achieved solely through tumor reduction before considering epoetin. If a rise in hemoglobin level is not observed after chemotherapy, epoetin should be used in accordance with the criteria outlined above for chemotherapy-associated anemia if clinically indicated. Blood transfusion is also a therapeutic option.

${ }^{*}$ From Rizzo et al (17). Use of epoetin in patients with cancer: evidence-based clinical practice guidelines of the American Society of Clinical Oncology and the American Society of Hematology. J Clin Oncol. 2002;20:4083-4107. Reprinted with permission from the American Society of Clinical Oncology. 